\title{
EREBEA
}

Revista de Humanidades y Ciencias Sociales

Núm. 9 (2019), pp. 105-132

ISSN: 0214-0691

http://dx.doi.org/10.33776/erebea.v9i0.3789

\section{PAISAJE, PROCESOS TERRITORIALES, TRANSFORMACIONES PAISAJÍSTICAS Y PERCEPCIÓN SOCIAL EN LA COMARCA DE LA AXARQUÍA (MÁlAGA) ${ }^{\mathrm{I}}$}

\author{
Matías Mérida Rodríguez \\ Universidad de Málaga
}

\section{RESUMEN}

La comarca de la Axarquía (Málaga) posee una marcada identidad paisajística, derivada de la presencia de montañas medias con benignas condiciones climáticas, que ha traído consigo una antigua y profunda humanización del territorio a partir de su desarrollo agrario. Estas cualidades permiten actualmente el desarrollo conjunto de diversos procesos territoriales, como el crecimiento urbano, el desarrollo del turismo y la expansión de nuevas modalidades agrícolas en unas condiciones relativamente equiparables, una singularidad en el litoral mediterráneo andaluz. En las últimas décadas, un nuevo proceso territorial, el turismo residencial, se ha propagado de forma intensa. El artículo analiza los rasgos del paisaje de la comarca, sus recursos paisajísticos, los diversos procesos territoriales experimentados y las transformaciones paisajísticas producidas, $\mathrm{y}$ explora la percepción social de estos cambios.

Palabras Clave

Paisaje; procesos territoriales; transformaciones del paisaje; percepción del paisaje; Axarquía.

Fecha de recepción: 20 de noviembre de 2019 Fecha de aceptación: 5 de diciciembre de 2019

\section{Abstract}

The Axarquía region (Málaga) has a strong landscape identity, derived from the presence of medium mountains with benign climatic conditions, which has brought with it an ancient and deep humanization of the territory from its agrarian development. These qualities currently allow the joint development of various territorial processes, such as urban growth, tourism development and the expansion of new agricultural modalities in relatively comparable conditions, a singularity in the Andalusian Mediterranean coast. Recently, a new territorial process, residential tourism, has spread intensely. The article analyzes the features of the landscape of the region, its landscape resources, the various territorial processes experienced and the landscape transformations produced, and explores the social perception of these changes.

\section{KeYwords \\ Landscape; territorial dynamics; landscape changes; landscape perception; Axarquía.}

1 Este trabajo se enmarca en el proyecto de investigación: Percepción social de la urbanización dispersa en entornos litorales mediterráneos y aplicación a la formulación de objetivo de calidad paisajística, financiado por el Ministerio de Economía y Competitividad (Proyectos de Excelencia. Código: CSO2015-67659-P). 



\section{INTRODUCCIÓN}

La comarca de la Axarquía se localiza en la parte oriental de la provincia de Málaga, entre las montañas béticas y el mar mediterráneo, sobre una superficie ligeramente por encima de los $1.000 \mathrm{~km}^{2}$ y una población censada de unos 210.000 habitantes, lo que se traduce en un densidad media de población elevada, unos $210 \mathrm{~h} / \mathrm{km}^{2}$, sobre todo si tenemos en cuenta la naturaleza montańosa de la mayor parte de sus terrenos. Un territorio, por tanto, altamente humanizado que se organiza administrativamente en 31 municipios, entre los que sobresale por sus dimensiones, su población y su localización central el de Vélez Málaga, que ostenta la capitalidad comarcal.

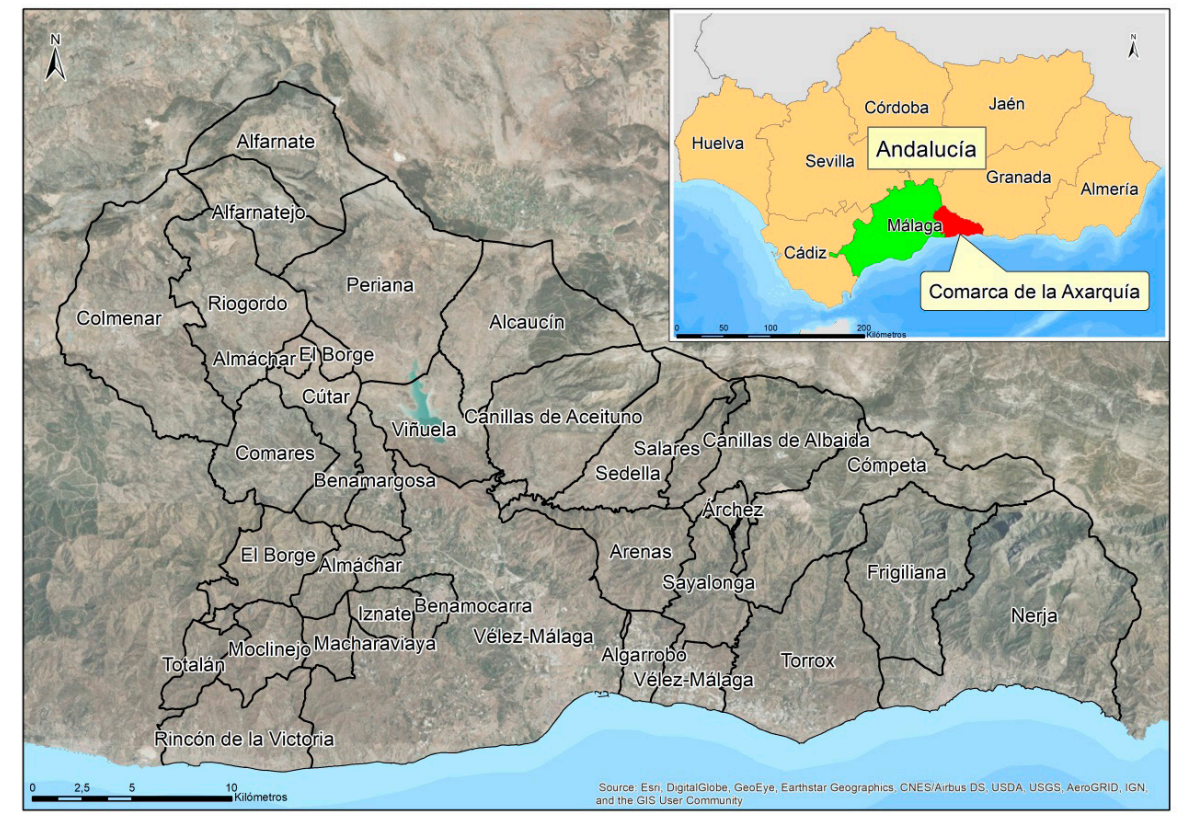

Figura no $n^{\circ}$. Localización y división administrativa de la comarca de la Axarquía. Elaboración propia.

Se trata de una comarca que combina una marcada identidad paisajística con un intenso dinamismo territorial, tanto en las zonas urbanizadas y en el litoral 
como también en su espacio rural, que se traduce en la coexistencia de profundos cambios paisajísticos, algunos de ellos muy drásticos, en un difícil equilibrio con el mantenimiento de un carácter del paisaje bien definido, reconocible y valorado. La coexistencia entre la dinámica territorial y la esencia paisajística tradicional le proporciona igualmente una acusada singularidad, debido a la especificidad de algunos de estos procesos territoriales, como la urbanización difusa en espacios rurales o la expansión de los frutales subtropicales. Además de implicar un claro deterioro del paisaje tradicional, en cierta medida los cambios paisajísticos, al mismo tiempo, mantienen e incluso acentúan la singularidad paisajística de la comarca.

Este artículo se marca como objetivos analizar las particularidades paisajísticas de la comarca, sus causas, los procesos territoriales y las dinámicas socioeconómicas que se han desarrollado sobre ellas y sus consecuencias paisajísticas. Igualmente, persigue explorar cuál es la percepción entre la población de estas transformaciones del paisaje y de los nuevos paisajes generados, conectando de este modo con la noción de paisaje contenida en el Convenio Europeo del Paisaje (Council of Europe, 2000).

El trabajo se estructura en diversos apartados que constituyen al mismo tiempo sus diversas fases metodológicas. En primer lugar se analizan los fundamentos naturales del paisaje. En segundo lugar se desarrolla su proceso de construcción histórica, recogiendo los diversos procesos territoriales experimentados y sus huellas en el paisaje actual. En tercer lugar, se analizan las dinámicas territoriales actuales y sus repercusiones paisajísticas. Finalmente, se aborda el estudio de percepción del paisaje, tanto a través de las representaciones culturales como mediante datos aportados por estudios de percepción social realizados directamente a la población.

\section{Los FUNDAMENTOS NATURALES DEL PAISAJE}

Fisiográficamente, se trata de una comarca montañosa, delimitada al este y al norte por un cinturón de sierras calcáreas de carácter rocoso y escasa aptitud agronómica entre las que destacan por su parte oriental la sierra de Tejeda, que alcanza los 2.000 metros en su cumbre, el pico de la Maroma, prolongada hacia el sureste, prácticamente sin solución de continuidad, por la de Almijara, que sitúa sus principales cumbres por encima de los 1.500 metros, y contacta directamente con el mar en el litoral de Nerja. Ambas sierras, estructuralmente pertenecientes al Complejo Alpujárride de las Unidades Internas de las Cordilleras Béticas, condicionan, por su naturaleza marmórea, el aprovechamiento agrario y alzan un murallón marmóreo de unos 40 kilómetros de largo que sirve de contundente separación entre las provincias de Málaga y Granada y que dificulta, aunque no impide, la comunicación entre ambas. Paisajísticamente, constituyen el telón de fondo oriental de la comarca. 


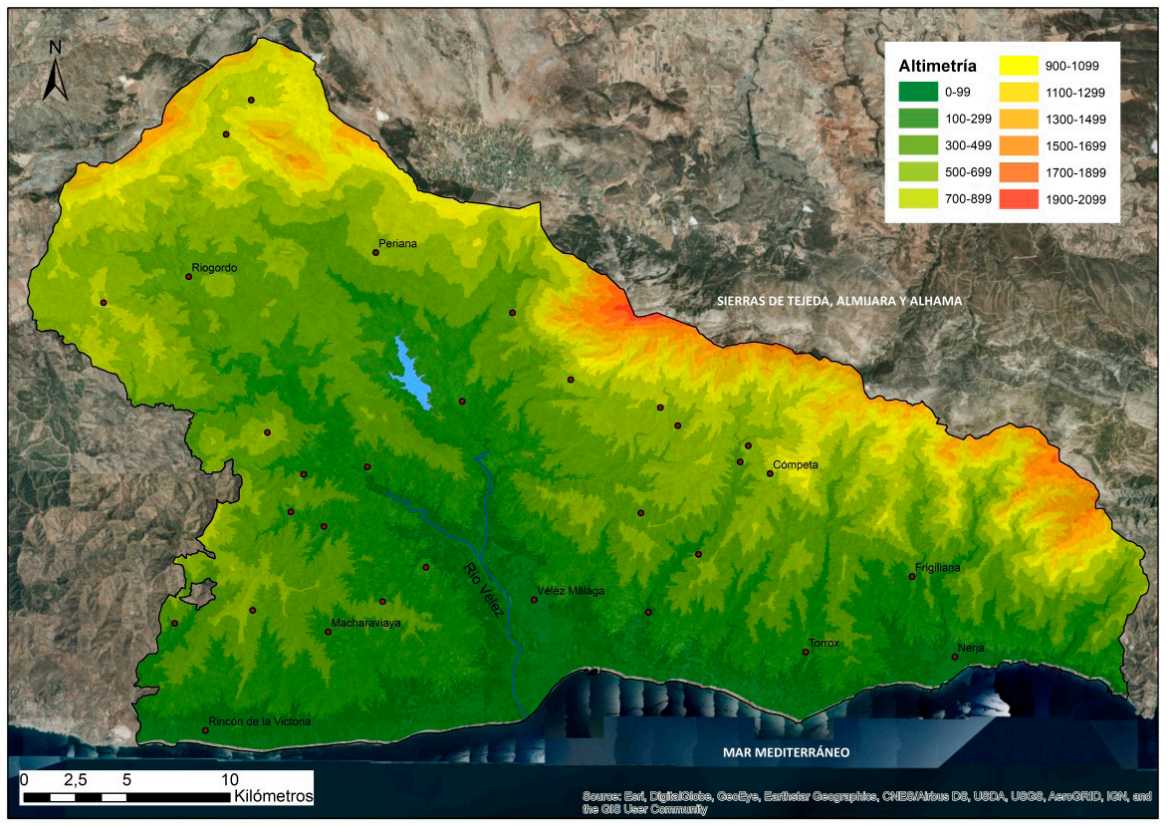

Figura 2. Mapa hipsométrico de la zona de estudio. Fuente: DERA (Junta de Andalucía). Elaboración propia.

Al norte de la comarca se dispone la sierra de Alhama, de materiales calizos subbéticos, con unos 1400 metros de altura en sus cumbres, separada del macizo de Tejeda por el denominado Boquete de Zafarraya, una marcada discontinuidad en la línea de cumbres de gran protagonismo visual que facilita la conexión de la Axarquía con los llanos de Zafarraya y por extensión con las comarcas de Loja y Alhama de Granada. Más al norte, prácticamente dispuestas de forma paralela a la de Alhama, aparecen las también subbéticas sierras de Camarolos y del Jobo, cuyas cumbres se sitúan en torno a los 1.400 y 1.600 metros de altitud; entre esta alineación y la de la sierra de Alhama se sitúa una zona depresionaria donde se localizan los núcleos de Alfarnate y Alfarnatejo, ambos emplazados cerca de los 900 metros de altura, que supone también, a través de su prolongación por el puerto de los Alazores, una histórica conexión con la granadina comarca de Loja. Desde el punto de vista paisajístico, estas alineaciones septentrionales suponen el cierre visual de la comarca. Aunque son menos contundentes que la alineación oriental, presentan también vigorosas formas, con abruptos escarpes.

Por el oeste el límite es mucho más difuso, conformado por los Montes de Málaga, una alineación de menor altura (sobre los 1.000 metros) y de carácter masivo, sin unos límites internos bien definidos, más que la línea de cumbres que forman los picos de La Reina y Santopitar, entre 900 y 1.000 metros, y su prolongación hacia el mar. Se trata de un conjunto de media montaña, de 
materiales pizarrosos del Complejo Maláguide de las Unidades Internas de las Cordilleras Béticas, morfológicamente de formas redondeadas, a modo de domos, pero al mismo tiempo con importantes pendientes por sus flancos que, como veremos más adelante, no impide su aprovechamiento humano. En ciertos puntos, sobre todo al oeste, afloran materiales calcáreos igualmente maláguides, produciendo relieves en resalte más vigorosos, tanto en la costa (Cerro Juan, El Cantal) como en el interior (Mazmullar, Comares), que destacarán visualmente respecto al paisaje existente en su entorno.

El interior de la comarca, articulado por el valle del río Vélez, el principal colector de la comarca, con unos 70 kilómetros de recorrido, está formado mayoritariamente por montańas medias, entre los 500 y los 1000 metros de altitud, que suponen un escalón intermedio entre las alineaciones más elevadas que circundan la comarca y la llanura litoral o el valle bajo del río Vélez, las únicas zonas relativamente llanas existentes en la comarca, dispuestas a modo de contrafuertes de las sierras más elevadas, bien de la alineación principal de los montes de Málaga, al oeste, o bien de las sierras de Tejeda y Almijara, al este. Salvo en algunos puntos, responden igualmente a un relieve generado sobre materiales pizarrosos y esquistosos de cumbres redondeadas y flancos de pendientes más acusadas, provocadas por la incisión de la red fluvial, bien de los afluentes del río Vélez o bien de los cortos ríos que desembocan directamente en el mar, como el Algarrobo o el Torrox. La naturaleza deleznable de sus materiales ha permitido históricamente el aprovechamiento agrario de sus terrenos, a pesar de su difícil orografía.

En la parte septentrional de la comarca, entre las montañas medias y el doble cierre calcáreo septentrional, se extiende una zona depresionaria, de suaves colinas, el denominado pasillo de Colmenar-Periana, colgado a unos 500 metros de altura. Formado por materiales de tipo flysch, perteneciente a las Unidades Intermedias de los Sistemas Béticos, alterna litológicamente arcillas y areniscas, y representa un espacio de aprovechamiento agrario prácticamente continuo, sobre suelos de clara aptitud agronómica, solo interrumpido por los afloramientos areniscosos, y con un hábitat concentrado en núcleos de mayores dimensiones, como Periana o Riogordo que los que se pueden encontrar en las áreas montañosas. Su topografía supone, paisajísticamente, un cambio nítido respecto a las zonas montañosas circundantes, que se plasmará en unos procesos territoriales y unos usos del suelo diferenciados de los del resto de la comarca y más conectados con los existentes en el interior de Andalucía.

Como se ha señalado anteriormente, las zonas llanas son escasas en la comarca y se circunscriben al valle bajo del río Vélez y a la llanura litoral, estrecha en líneas generales pero algo más amplias en la desembocadura de los ríos. Reúne los mejores suelos desde el punto de vista agronómico, especialmente en el valle del río Vélez, además de las zonas más aptas para la urbanización en general y para el 
desarrollo turístico en particular así como para el trazado de las infraestructuras de comunicaciones. El litoral, morfológicamente, combina costas arenosas, mayoritarias, con acantilados, que afloran, entre otros puntos, en Rincón de la Victoria, Torrox y, sobre todo, en Nerja, en la parte oriental de la comarca. Aunque su extensión superficial sea reducida, su transcendencia respecto a la ocupación y el aprovechamiento humano es muy elevada. Desde el punto de vista paisajístico, estas costas acantiladas generan paisajes de gran calidad estética.

La disposición del relieve tiene un importante efecto climático, ya que suponen una barrera de protección frente a los vientos fríos del norte al resto de la comarca, a modo de abrigo montañoso. Este hecho, unido a la cercanía del mar y a la frecuente disposición meridional de sus laderas, proporciona una especial benignidad climática, más apreciable en el litoral y en la zona central de la comarca. Las temperaturas medias de la comarca oscilan entre los 19 y los 15 grados de media anual, desde el sur hasta el norte, haciendo una inflexión por el valle del río Vélez (Senciales, 2007). Igualmente, las mínimas absolutas se sitúan generalmente en valores positivos, exceptuando la parte septentrional y por supuesto las montańas, donde la presencia de nieve es habitual durante el invierno en las cumbres más elevadas. Estas suaves condiciones térmicas tendrán evidentes repercusiones en el desarrollo agrario, urbanístico y turístico de la comarca, generando claras potencialidades económicas. Por otro lado, las precipitaciones medias se sitúan por debajo de los valores provinciales, aunque con grandes disparidades: de los $400 \mathrm{~mm}$ anuales de la costa a los 900 de las zonas montañosas, aunque la mayor parte del territorio se sitúa entre los $400 \mathrm{y}$ los $600 \mathrm{~mm}$. Esto da lugar a unos recursos hídricos limitados, sobre todo durante la estación estival. Mientras que las aguas superficiales son, en general, escasas, abundan los acuíferos, tanto detríticos (Velez Málaga, Torrox, Nerja) como sobre todo los carbonatados, presentes en las sierras del norte y este de la comarca. Las surgencias de agua, en el contacto de los materiales calcáreos con los esquistos, han determinado la localización de numerosos núcleos de población de la comarca, muchos de ellos emplazados a cotas similares.

Para aumentar los recursos hídricos disponibles, tanto para abastecimiento como para la agricultura, se construyó en la década de los 80 el embalse de la Viñuela, sobre el río Guaro, sobre unas 600 has. de terreno, y que constituye un elemento central de la parte septentrional de la comarca. Paisajísticamente constituye un indudable recurso, por la atracción paisajística del agua, y su puesta en funcionamiento supuso una clara revalorización de los terrenos circundantes.

\section{El proceso de ConstrucCión histórica del paisaje y SUS Vestigios.}

A pesar de su carácter mayoritariamente montañoso, la Axarquía constituye un territorio intensamente humanizado. Aunque se ha acentuado en el último medio siglo, la antropización del espacio se ha venido desarrollando a lo largo 
de la historia, hundiéndose incluso en la prehistoria, con numerosos vestigios que perviven en la actualidad, habitualmente bajo la figura de Bien de Interés Cultural. Del periodo prehistórico quedan numerosas muestras, algunas de ellas muy notables, que parte de la existencia de numerosas cuevas y abrigos en los materiales calcáreos. El conjunto de cuevas de La Araña (Málaga), Rincón de la Victoria, Alcaucín (cueva de Zafarraya) y especialmente la cueva de Nerja suponen ejemplos muy relevantes en el marco mediterráneo y cuentan con un importante valor patrimonial. En los comienzos de la Historia Antigua, el litoral oriental fue asentamiento de colonias fenicias, de las que quedan valiosos vestigios, como los poblados de Toscanos y Mezquitilla. La época romana supuso la continuidad del poblamiento en el litoral, con asentamientos como Maenoba (habitualmente considerada como emplazada en la actual Torre del Mar) y numerosas villas, siendo la existente junto al faro de Torrox el vestigio más relevante. En esta época el territorio se articulaba por la calzada que recorría el litoral, que aflora en algunos puntos, como en las cercanías de Maro (Gozálvez, 1984).

La época medieval islámica fue un periodo de especial dinamismo económico en la construcción del paisaje actual. Durante el mismo, la Axarquía y la costa oriental experimentaron un gran desarrollo agrícola, con productos como la seda, higos, pasas, caña de azúcar y viñedo (Justicia, 1984). Esto implicó la proliferación de alquerías en el interior de la comarca, germen de la mayoría de los actuales núcleos, además de la formación y desarrollo del núcleo principal, Velez Málaga, a partir de su castillo. Incluso se cuentan con asentamientos de época mozárabe, como el de Mazmullar (Comares). Además del emplazamiento y de la morfología interna de los pequeños núcleos interiores, el periodo islámico ha legado muestras arquitectónicas tan señaladas como el alminar de Árchez.

Además de los núcleos, en esta época medieval se trazó el Camino Real que conectaba con Granada a través de Zafarraya, embrión del actual eje viario transversal. Igualmente se erigieron fortificaciones en lugares estratégicos, como el castillo de Vélez, el de Zalía, el de Bentomiz o el de Comares, verdaderos hitos del paisaje en la actualidad, además de constituir valiosos paisajes patrimoniales, aunque en diferente estado de conservación. Igualmente, algunas de las torres almenaras litorales de la Edad Moderna se construirán sobre primitivas fortificaciones litorales nazaríes (Zoido y Rodríguez, 2015). Mientras tanto, las zonas puramente serranas permanecían al margen del proceso de humanización por los severos condicionantes físicos a la actividad agraria y quedaron en buena parte como reserva forestal. La parte norte de la comarca, sobre terrenos menos accidentados, continuó con su tradicional dedicación cerealista (Gómez Moreno, 1983).

La conquista cristiana, a finales del siglo XV, coincidió con el comienzo de la Edad Moderna. Durante esta etapa, la principal transformación del paisaje la provocó la expansión de la vid, que experimento un crecimiento paulatino 
que alcanzó su cénit a finales del siglo XVIII. Esto provocó una importante deforestación en las montañas esquistosas y, simultáneamente, el crecimiento de la llanura litoral debido a la intensa erosión generada. En la planicie litoral se expandió progresivamente el cultivo de la cańa de azúcar, apareciendo los primeros ingenios preindustriales, como el de Maro, del siglo XVI, extendiéndose de manera más importante en el siglo XVIII, llegándose a contabilizar una veintena durante el siglo XIX. Esta actividad provocó una intensa deforestación en las sierras cercanas, quedando como única excepción los bosques de la Armada, localizados en la parte meridional de la sierra de Almijara, especialmente en Nerja; la deforestación supuso también la carencia de combustible y la consiguiente crisis de esta producción preindustrial a finales del siglo XVIII.

Desde el punto de vista militar, los primeros siglos de la Edad Moderna estuvieron condicionados por la sublevación de los moriscos y las incursiones berberiscas, que motivaron que se erigieran una red de torres vigías en el litoral mediterráneo. Concretamente, en el litoral oriental malagueńo se contabilizan 17 torres almenaras, que constituyen en la actualidad puntos referenciales de primer orden, aunque su grado de conservación y, sobre todo, sus condiciones de visibilidad, sean muy variables entre unas y otras. Más adelante, en el siglo XVIII, y por motivos semejantes, combatir la piratería, en este caso fundamentalmente británica, se construyeron en el litoral fortalezas de mayor entidad, como el castillo de Bezmiliana, en Rincón de la Victoria. De esta etapa borbónica data también la mejora de las comunicaciones, como la construcción del camino de Málaga a Vélez, un elemento patrimonial que no está puesto en valor pero que cuenta con puntos tan significativos históricamente como el arco de entrada al municipio de Málaga, en un lamentable grado de abandono en la actualidad.

El siglo XVIII tuvo también su importancia en el plano industrial. Algunos de las primeras fábricas de la provincia tuvieron su emplazamiento en esta comarca, como la Real fábrica de naipes de Macharaviaya, en la que jugó un papel determinante la familia Gálvez, entonces muy influyente en el gobierno de Madrid, y natural de dicho municipio, o la fábrica de papel del Río de la Miel, íntimamente ligada a la anterior en sus comienzos, y que aprovechaba la fuerza motriz del río. Aunque con un notable grado de deterioro, todavía quedan restos de ambas construcciones.

El siglo XIX supuso el desarrollo de la industria vitícola y la modernización del sector azucarero, con el consiguiente relanzamiento del cultivo de la caña de azúcar, esta vez con fuertes inversiones empresariales. Las nuevas instalaciones tenían un carácter plenamente industrial, como las fábricas de Torre del Mar y Nerja, así como infraestructuras asociadas, como el conocido acueducto del Águila, también en Nerja. Estas construcciones perviven en la actualidad, en desiguales estados de conservación, constituyendo elementos referenciales del paisaje. Esta etapa industrial álgida duró hasta comienzos del siglo XX, fecha a 
partir de la cual la competencia del azúcar de remolacha (y de otros cultivos o usos del suelo más competitivos) fue cada vez más intensa, languideciendo el cultivo de la cańa durante el resto del siglo XX, asociado a la producción de ron (Justicia, 1988). Desde finales de los años 80 no quedan ya explotaciones, desapareciendo, al mismo tiempo, un cultivo y un paisaje patrimonial de enorme singularidad en el contexto europeo.

Muy importante también fue la expansión de la vid, habitualmente en pequeñas explotaciones en las zonas montuosas, de suelos pedregosos, dando lugar a un denso hábitat diseminado que alcanzó los 2.000 lagares en la comarca (Blanco, 1997) y decenas de miles de hectáreas de las 112.000 contabilizadas en el conjunto de la provincia (Santiago y Guzmán, 2007). La producción se destinaba tanto a vinos como, especialmente, a pasas, que gozaban de una gran fama en el exterior. Sin embargo, este paisaje de monocultivo vitícola quedó muy afectado de la plaga de la filoxera, a finales del XIX y que precisamente surgió en un lagar de Moclinejo. A pesar de que hubo intentos de recuperación, no se alcanzó el esplendor anterior, y aunque el cultivo de la vid ha continuado en la Axarquía, una buena parte de las tierras fueron sustituidas por cultivos arbóreos de secano, como el almendro y el olivar. No obstante, la producción vitícola continúa, así como la de pasas, producidas de forma artesanal en los característicos paseros. Viñas y paseros, como herencia de un pasado próspero, constituyen una parte muy relevante de la identidad paisajística de la comarca.

El comienzo del siglo XX trajo consigo avances en las comunicaciones, como el desarrollo ferroviario, con la puesta en funcionamiento del tren litoral, posteriormente prolongado hacia el norte hasta Zafarraya, con varios tramos de cremallera. Puntos relevantes paisajísticamente de estos trazados fueron las estaciones, que jalonan el litoral con una fábrica estandarizada y que hoy en día han sido reconvertidas en espacios públicos de diversa funcionalidad. Paisajísticamente, pueden considerarse en estas localidades como elementos referenciales de su paisaje. El trazado ferroviario se desmanteló en los años 60, siendo en algunos puntos reutilizados como ejes viarios o, en la actualidad, senderos, que discurren entre túneles en la zona de El Cantal (Rincón de la Victoria), y cuyo recorrido incrementó su relevancia histórica por haber sido escenario de la conocida como desbandá, la trágica huida de población civil de Málaga hacia Almería por el temor al avance de las tropas franquistas.

Por su parte, las comunicaciones viarias también experimentaron un cierto desarrollo en la primera mitad de siglo. Además de algunos recorridos interiores, especialmente dos ejes: el litoral y el transversal, de conexión de Vélez Málaga con Zafarraya. En el segundo caso, su recorrido coincide, en líneas generales, con el histórico; por el contrario, el eje litoral fue sustituido por trazados de mayor capacidad (N340, Autovía A7), conservándose no obstante aún hoy restos del antiguo recorrido, especialmente atractivos paisajísticamente en las 
zonas de acantilados, por lo que son frecuentemente utilizados como miradores improvisados.

\section{Dinamicas territoriales CONTEMporáneas}

A partir de mediados del siglo XX, el paisaje de la Axarquía experimenta notables cambios, debidos tanto a la modernización agrícola y la consiguiente crisis de la agricultura marginal como al desarrollo urbano y turístico del litoral. La crisis de los cultivos tradicionales de secano condujo a su progresivo abandono, y al mismo tiempo al despoblamiento de las zonas interiores, especialmente acusado en el hábitat disperso. Un gran número antiguas construcciones rurales aisladas se convirtieron así en ruinas. Diferente ha sido la evolución de las tierras bajas y de las primeras estribaciones montañosas. Sobre estos terrenos se ha producido en las últimas décadas la expansión de dos nuevas modalidades y cultivos agrarios de gran rentabilidad, los invernaderos y los frutales subtropicales, aprovechando la benignidad térmica y la mayor disponibilidad de recursos hídricos tras la puesta en funcionamiento del embalse de La Viñuela a finales de los años 70. Los invernaderos ocupan cerca de 800 hectáreas, distribuidas en un primer momento en la zona litoral más oriental (Torrox, Algarrobo, Nerja) pero que actualmente han escalado las primeras laderas montañosas en terrazas y se han extendido por la parte central y, en menor medida, occidental del litoral. Mayor ha sido la expansión de los cultivos subtropicales. Los aguacates y, más recientemente, el mango, han tenido y siguen teniendo un extraordinario desarrollo, amparados en la existencia de amplios mercados en Europa, sólo condicionados por los problemas con el suministro hídrico. Un desarrollo que en un primer momento se produjo en forma de terrazas en las colinas de las zonas bajas pero que con posterioridad se han expandido hacia los fondos de valle e incluso hacia laderas meridionales de pendientes mucho más pronunciadas, sobre las que se han llevado a cabo intensos movimientos de tierras para crear las terrazas, de indudable impacto paisajístico (fig. 3).

En la actualidad, la mayor expansión corresponde al mango, cuyas técnica de cultivo no requiere de aterrazamiento aunque si, lógicamente, de eliminación de la vegetación preexistente en estas laderas y de considerables movimientos de tierras. Su expansión por terrenos situados a cotas más elevadas de la fijada por la Administración hidráulica (140 metros) ha acrecentado el impacto en el paisaje montañoso de la comarca. El resultado, una vez que estos cultivos han adquirido porte arbóreo, es un paisaje de gran verdor y densidad vegetal, que contrasta con el aspecto más árido de los montes cercanos. Se trata, en cierta medida, de un paisaje engańoso, ya que se sustenta en unas aportaciones de agua que no están, cuando menos, plenamente garantizadas. Espacialmente, las aproximadamente 10.600 hectáreas de cultivos de aguacate y mango se extienden sobre todo por la 
parte central de la comarca, a lo largo del valle del río Vélez, y por el litoral, en mayor medida en su parte oriental que en el occidental.

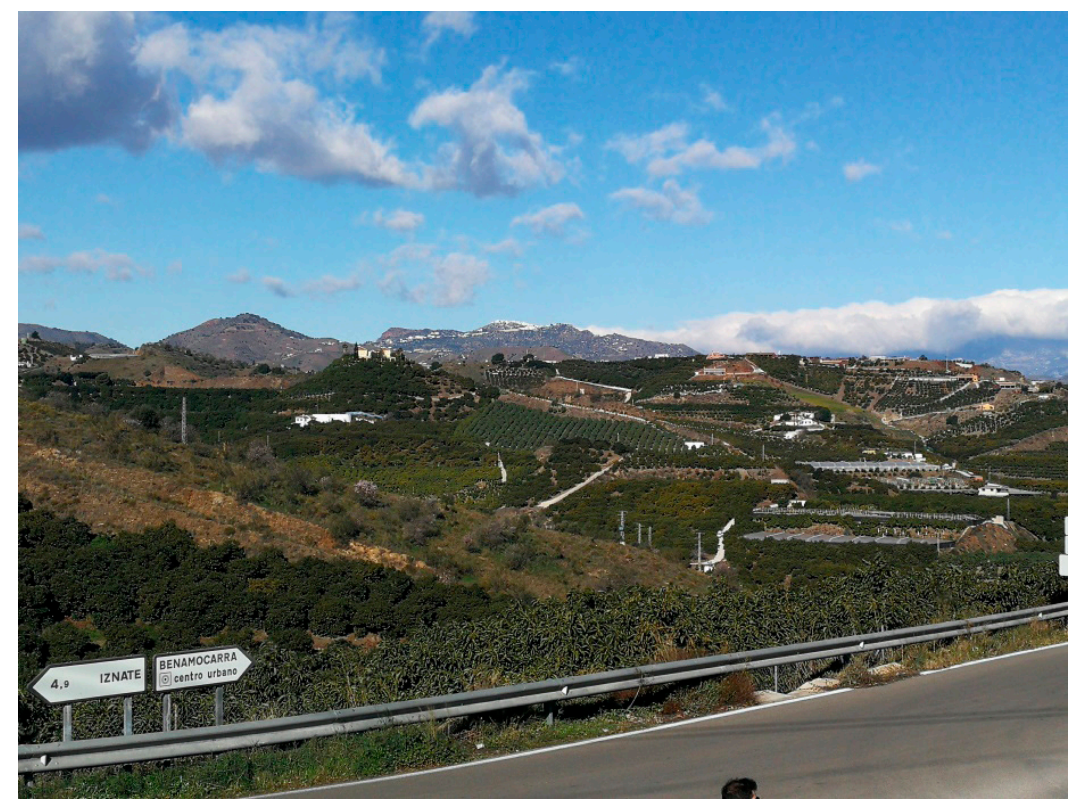

Figura 3. Cultivos subtropicales de regadío. Elaboración propia.

La segunda dinámica territorial que se experimenta en la segunda mitad del siglo XX tiene que ver con el crecimiento de las zonas urbanizadas, especialmente en la parte litoral, ligado tanto al turismo como, en mayor medida, al crecimiento urbano: desarrollo metropolitano de la capital provincial en el caso de Rincón de la Victoria y concentración del éxodo rural de la comarca en el caso de la capital comarcal, Vélez Málaga. La mayor parte de los 211.000 habitantes de la comarca se sitúan en los municipios litorales (Rincón de la Victoria, Torrox, Nerja) y sobre todo en la capital comarcal, Vélez Málaga, situada en una zona próxima a la desembocadura del río Vélez y que organizada en dos grandes núcleos que tienden a confluir (la propia Vélez Málaga y Torre del Mar) concentra con sus 80.817 habitantes al $38.4 \%$ de la población de la comarca.

El turismo, estrechamente vinculado a la franja litoral, ha adquirido un mayor desarrollo en la parte central y oriental de la comarca, y tiene algunos rasgos particulares que diferencia a zonas costera de la más intensamente ocupada costa occidental malagueña. En primer lugar, el desarrollo fue más tardío y menos intenso. La lejanía del aeropuerto de Málaga, las menores disponibilidades hídricas y la carencia de buenas comunicaciones lastraron durante los años 60 su crecimiento, limitado al caso entonces puntual de Nerja, que tuvo en el descubrimiento de su Cueva un atractivo rápidamente derivado a su litoral y que 
se tradujo en la inauguración del Parador Nacional en 1965. Ya en las décadas siguientes se desarrollarían los característicos apéndices costeros-turísticos de los núcleos tradicionales, como Algarrobo Costa o Torrox Costa, respondiendo a este esquema también, en cierta medida, el núcleo litoral de Torre del Mar. En segundo lugar, otro rasgo diferenciador con la costa occidental lo representa la procedencia de los turistas, con un peso elevado del turismo alemán en esta parte del litoral. Y en tercer lugar, la costa oriental apostó por un modelo basado más en los apartamentos que en los hoteles, siendo la planta hotelera relativamente escasa en términos comparativos respecto a la costa occidental.

La tercera dinámica territorial significativa guarda relación, espacialmente, con los antiguos dominios del secano, es decir, las zonas montañosas interiores. Estas áreas acumulaban un caserío disperso en muchas ocasiones abandonado, así como núcleos con escasas alternativas al modo de vida agrario tradicional y mal comunicados, y por tanto con una dinámica demográfica regresiva. Sobre estos terrenos se va a registrar desde los años 80 un proceso de urbanización difusa vinculado a varios procesos territoriales, como la segunda residencia de la población local, en algunos casos primera residencia (a modo de rururbanización), y de forma muy especial el turismo residencial. Se produce una importante demanda de viviendas por parte de ciudadanos extranjeros, habitualmente jubilados, que buscan espacios confortables climáticamente y paisajísticamente atractivos, pero al mismo tiempo cercanos a unos servicios básicos de cierta calidad (sanitarios, emergencias, etc.).

En los primeros momentos la demanda se enfocó a la rehabilitación de las viviendas preexistentes, pero en poco tiempo se tradujo en la edificación de nuevas viviendas, adyacentes a las tradicionales o directamente en nuevos emplazamientos (fig. 4). La proliferación de viviendas, construidas mayoritariamente al margen de la legalidad urbanística, contó, cuando menos, con una gran laxitud e inacción de las administraciones implicadas, especialmente la municipal, así como de buena parte de la sociedad local, que se beneficiaba a corto plazo del impulso económico que supuso este desarrollo para el sector de la construcción. El resultado ha sido un crecimiento espectacular del número de viviendas dispersas en suelo no urbanizable, superando las 20.000 en la base de datos generada en el proyecto citado al principio del texto, la mayoría de ellas al margen de la legalidad. Esto ha generado numerosos problemas medioambientales (Yus, 2010), urbanísticos y de dotación de servicios. En la actualidad, la reciente crisis económica, junto con una mayor presión judicial, ha detenido este fenómeno, generando su resultado un gran desafío paisajístico. 


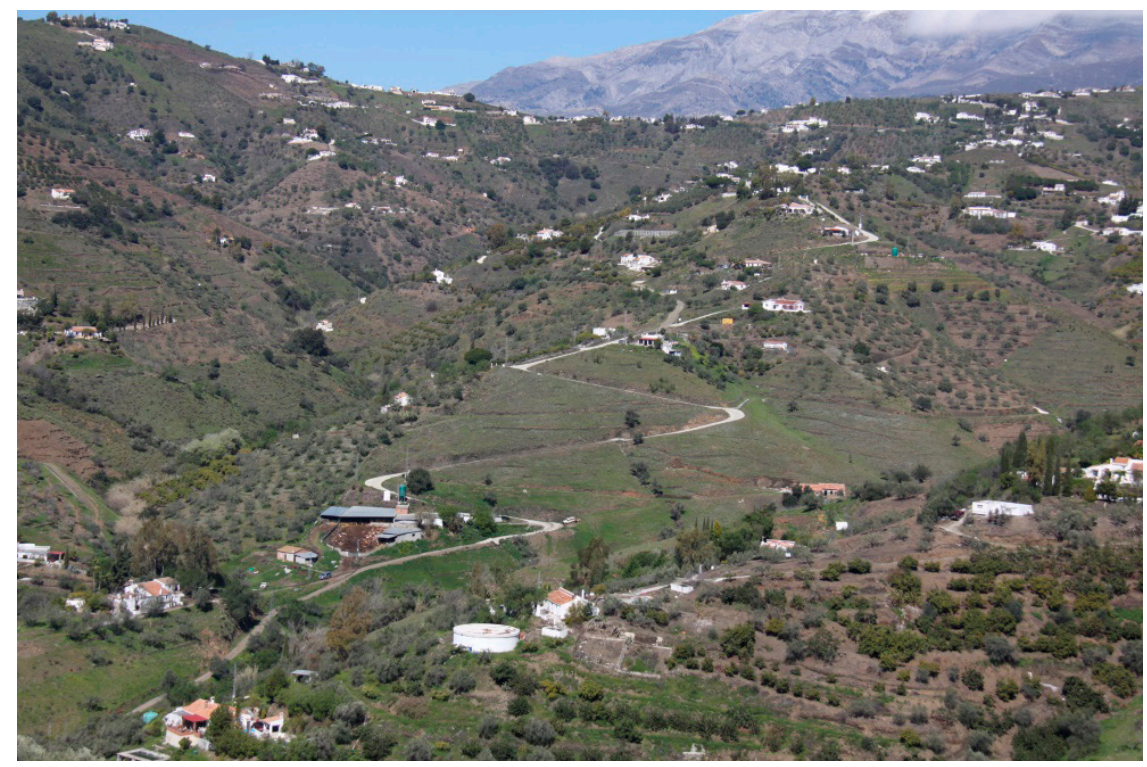

Figura 4. Urbanización dispersa sobre montañas medias. Elaboración propia.

Durante estas últimas décadas se asiste también al desarrollo de las infraestructuras en la comarca, estrechamente vinculado al crecimiento urbano, metropolitano y turístico, localizándose sobre todo en el litoral (autovía A7) y en la construcción de un nuevo eje transversal entre Torre del Mar y La Vińuela, que se prolonga hasta Casabermeja, al oeste. Ambos ejes, pero sobre todo el primero, de más entidad, ha supuesto también profundos cambios paisajísticos en la franja prelitoral, muy especialmente en la parte oriental, más montañosa, con grandes movimientos de tierra y profundas incisiones en las laderas que han generado fuertes impactos en el paisaje (figura 5).

Desde el punto de vista espacial, a diferencia de otras zonas litorales mediterráneas, las transformaciones paisajísticas experimentadas en las últimas décadas no se han circunscrito al espacio litoral, penetrando en amplias zonas del interior a través del valle bajo del río Vélez, como se puede deducir de la distribución espacial de las áreas urbanizadas y los regadíos en el mapa de usos del suelo de la comarca (fig. 6)

No obstante, se puede apreciar que existe una tendencia decreciente sur-norte en la intensidad de los cambios que se han producido en las últimas décadas. Aunque no existen límites tajantes entre los diversos procesos territoriales, en un corte transversal de la zona de estudio tomado de Google Earth, en la zona de Algarrobo (fig. 7), se puede dividir el territorio en franjas paralelas al mar y crecientes en altitud, y apreciar los procesos dominantes en cada nivel. Así, el espacio litoral aparece dominado por la urbanización, en núcleos o en 


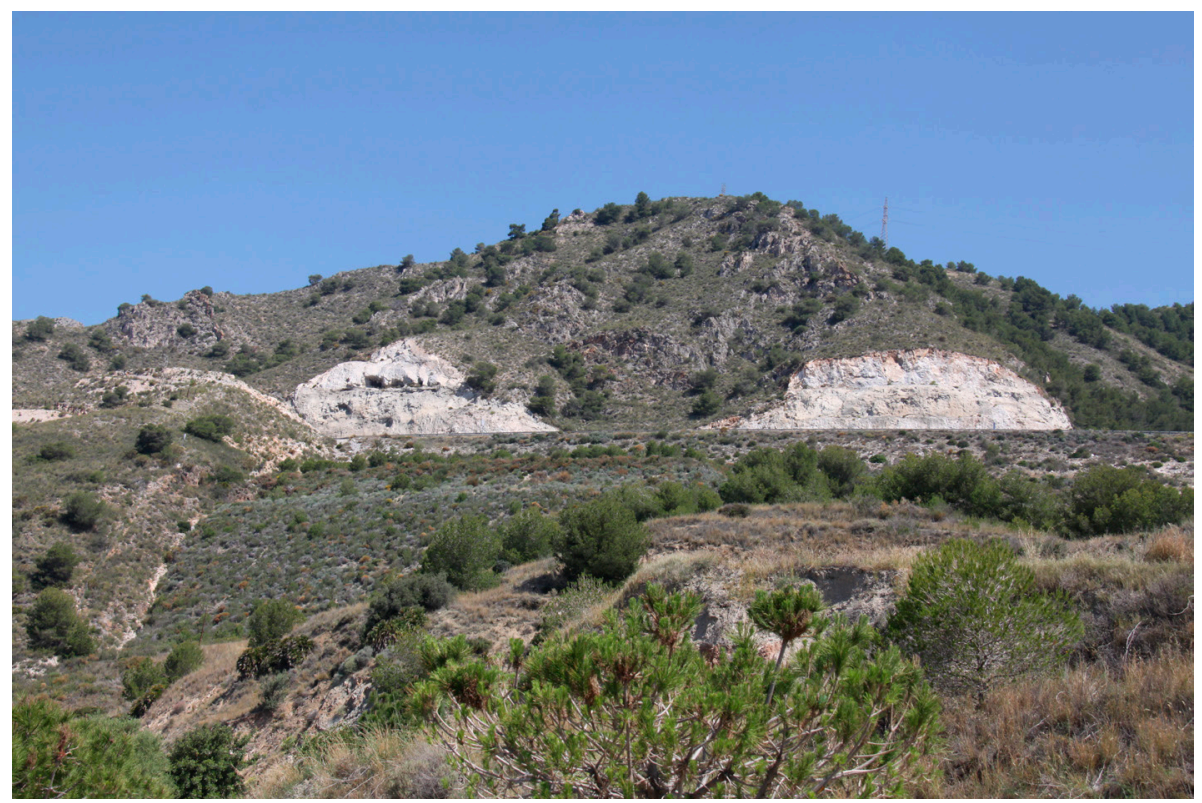

Figura 5. Taludes generados por la autovía A7 en el entorno litoral. Elaboración propia.

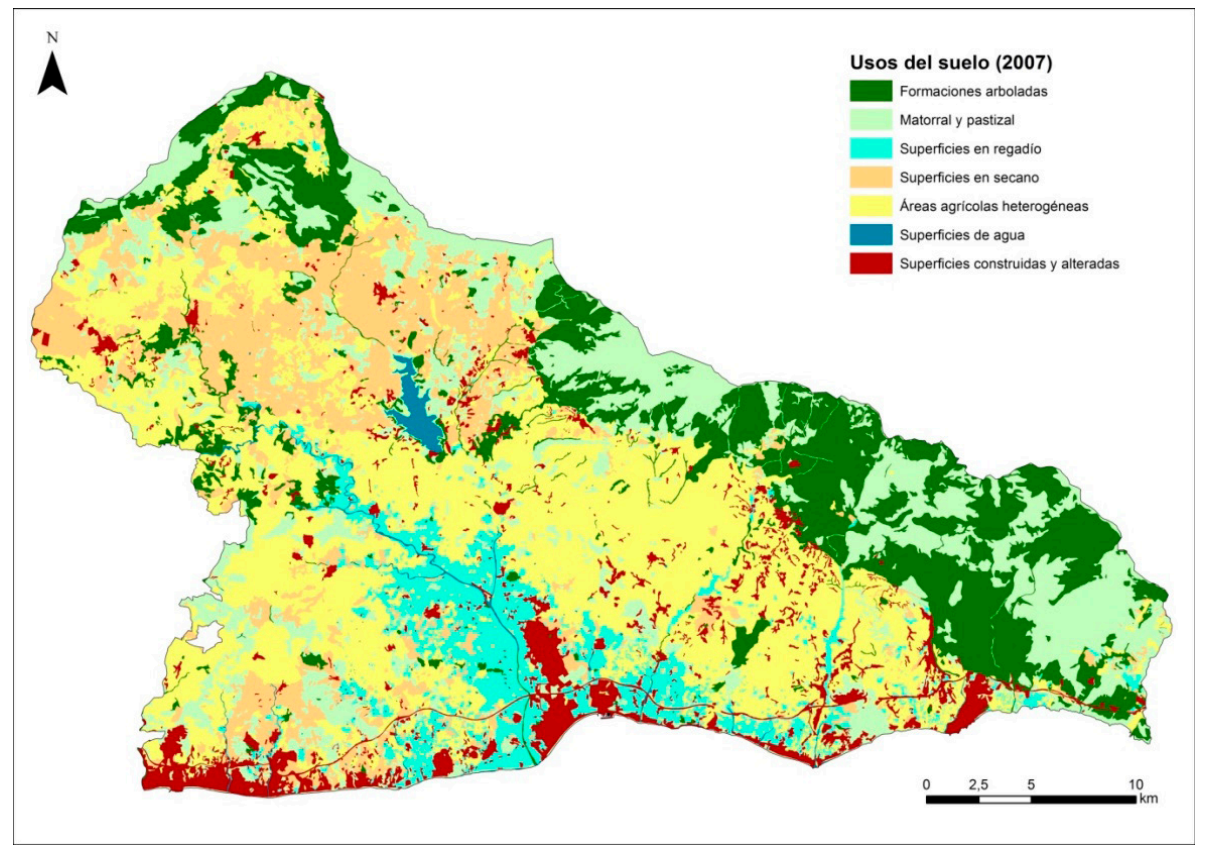

Figura 6. Mapa de usos y aprovechamientos del suelo. Fuente: REDIAM 2018. 
urbanizaciones más extensivas, aunque convive con parcelas agrícolas en segunda línea de playa. La siguiente franja, todavía en la llanura litoral, está dominada por la agricultura, tanto regadíos como invernaderos, con su hábitat disperso asociado. Subiendo en altitud, en las primeras estribaciones montañosas, dominan la escena los frutales subtropicales, normalmente en terrenos aterrazados, y en menor medida invernaderos. La cuarta banda se sitúa a una mayor altitud, sobre antiguos dominios del secano arbóreo, y está mayoritariamente ocupada por construcciones dispersas en una densidad muy elevada. Finalmente, la quinta franja la supondrían las altas sierras, donde se conserva la cobertura del suelo natural y que supondrían el marco escénico de la panorámica.

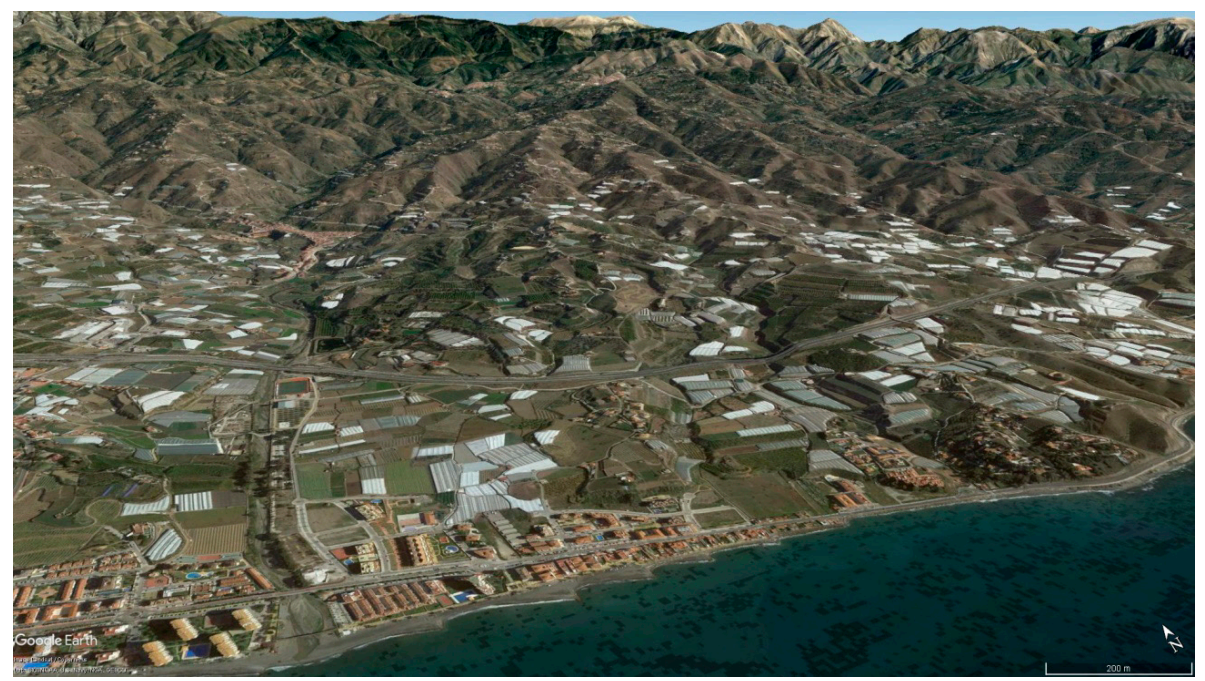

Figura 7. Imagen transversal sur-norte en el sector de Algarrobo. Fuente: Google Earth.

\section{Los VAlores paisajísticos de la comarCa y SU ReConocimiento.}

La Axarquía contiene recursos paisajísticos de diversa naturaleza y escala: paisajes naturales, paisajes agrarios, espacios litorales, hitos paisajísticos (naturales o construidos), paisajes de carácter cultural, así como elementos lineales o puntuales del paisaje, como carreteras históricas o construcciones tradicionales. Entre ellos destacan en primer lugar, si atendemos a su reconocimiento institucional, sus paisajes naturales. Circunscritos a las zonas de montaña calcárea que se dispone perimetralmente por la comarca, y a la franja litoral donde las sierras contactan con el mar en forma de acantilados, entre sus valores reconocido destaca su calidad paisajística, tanto intrínseca (paisajes agrestes, bosques y manchones de coníferas, acantilados) como extrínseca (telón de fondo de la comarca y presencia ineludible en las vistas, tanto terrestres como marítimas). El conjunto de sierras calcáreas fueron incluidas como Complejos Serranos de Interés Ambiental en el Plan Especial de Protección del Medio Físico de la Provincia de Málaga, de 1987. 
Con posterioridad, ya en los años 90, las sierras que conforman su alineación oriental, esto es, las sierras de Tejeda y Almijara, que en su momento constituían la Reserva Nacional de Caza homónima, fueron declaradas como Parque Natural. Los intentos de inclusión en el Parque Natural de la doble alineación septentrional no fructificaron. Posteriormente, las sierras más exteriores fueron declaradas LIC (Lugar de Importancia Comunitaria). Con la entrada en vigor del Plan de Ordenación Subregional de la Costa Oriental y Axarquía (2007), las sierras de la primera alineación (sierra de Alhama y su prolongación) han sido catalogadas como Zonas de Interés Territorial. A pesar de este menor nivel de protección, estas sierras conforman también paisajes abruptos, de gran calidad estética, que, asociados a las no infrecuentes precipitaciones en forma de nieve, incluso han generado su propia imagen de marca turística: los 'Pirineos del Sur'.

Por su parte, los acantilados de Maro, que se extienden hasta Cerro Gordo, ya en la provincia de Granada, también fueron objeto de protección en el PEPMF de la provincia, bajo la categoría de Espacios Naturales y Huertas de Nerja, y a finales de los años 80 fueron declarados como Paraje Natural en su parte más estrictamente natural, incluyendo una franja marítima. La zona de componente más agrario de la zona de acantilados, que da lugar a un paisaje de pequeñas parcelas abancaladas siguiendo las curvas de nivel, posee, junto a espacios de carácter más natural y al propio núcleo de Maro, otro nivel de protección, más antiguo (1968) y procedente de la legislación sobre patrimonio cultural. Se trata del área denominada Alrededores de Maro-Cueva de Nerja, perteneciente a la antigua figura de Parajes Pintorescos, que tras un periplo entre las legislaciones de espacios naturales protegidos y de patrimonio cultural, desapareció formalmente, quedando acogidos estos espacios bajo otras figuras de protección de la legislación cultural, habitualmente, como en este caso, la de Sitio Histórico. Las restricciones que esta figura de protección implicaba respecto al desarrollo urbanístico motivaron, en una época reciente, la llamativa petición de descatalogación de este espacio por parte del Ayuntamiento de Nerja. En esta misma línea, la protección como Zona de Interés Territorial de los espacios libres entre el Parque Natural y el Paraje Natural por el Plan de Ordenación Subregional de la Axarquía, fue anulada por el Tribunal Supremo a partir de un recurso del Ayuntamiento de Nerja por la existencia de derechos urbanísticos previos.

Al margen de esta zona más puntual, en general los paisajes agrarios de la comarca han recibido una menor atención que los naturales en materia de protección, quedando, en la práctica, como espacios destinados al dinamismo territorial, de todo tipo: cambios agrarios, infraestructuras, urbanización, equipamientos, etc. En alguna ocasión, las vegas fueron merecedoras de algunas figuras de protección, como fue el caso de los denominados Paisajes Agrarios Tradicionales de las vegas de Vélez, Algarrobo, Torrox o Nerja, entre otras, en el PEPMF de la provincia. 
Frente a estos casos, la montańa media axárquica, que en cierta medida podríamos considerar como el arquetipo paisajístico de la comarca, con sus cultivos arbóreos o arbustivos, entre los que destaca simbólicamente la vid y sus emblemáticos paseros, y con su característico poblamiento de pequeños núcleos y hábitat disperso agrario, no ha gozado, en líneas generales, de figura de protección alguna. Sin embargo, se trata de un paisaje celebrado, atractivo para el turismo y que por eso ha venido figurando en la publicidad turística de la comarca. Tomando como núcleo este tipo de paisaje, el antiguo ICONA, en su Inventario Nacional de Paisajes Sobresalientes, realizado entre 1975 y 1977, incluyó a una parte importante de la comarca, con la denominación de Axarquía, como muestra de paisajes agrarios mediterráneos. Esta concepción del paisaje, por otra parte, se podría considerar como muy avanzada en esa época, pero en realidad habría que considerar su inclusión como una excepción frente al dominio abrumador de paisajes naturales.

En relación al reconocimiento y protección de estos paisajes de dominancia cultural, además del Sitio Histórico de Maro-Cueva de Nerja antes mencionado, determinados espacios de la comarca están incluidos en el reciente Registro de Paisajes de Interés Cultural de Andalucía, elaborado por el Instituto Andaluz de Patrimonio Histórico. Por un lado, el denominado Paisaje de la Defensa Litoral de Maro a Cerro Gordo, prácticamente superpuesto al paraje natural, pero donde se realzan especialmente las construcciones defensivas que articulan el territorio. Por otro lado, el denominado Paisaje del paso de Zafarraya, en el que se resalta los valores arqueológicos, históricos y culturales de un espacio dispuesto a ambos lados del Boquete de Zafarraya como elemento central. Finalmente, el más representativo para la comarca, el llamado Paisaje de los pueblos de la Axarquía Occidental, circunscrito a terrenos de la margen derecha del río Velez (río Benamargosa, río Almachar), y donde la transformación de la montaña media no ha sido tan intensa, conservando caserío y usos del suelo tradicionales, como el viñedo, en una medida más apreciable. En cierta medida, este paisaje de interés cultural se podría considerar como heredero del catalogado en el antiguo Inventario Nacional de Paisajes Sobresalientes.

Todavía dentro de los paisajes culturales, algunos núcleos de la comarca tienen la consideración de BIC, en la categoría de mayor relevancia paisajística, la de Conjunto Histórico, como el centro histórico de Vélez Málaga, el núcleo de Macharaviaya y la mayor parte del de Frigiliana. Dentro de la categoría de Monumentos, destacan, por su dimensión paisajística, las fortalezas y las torres vigía del litoral o las torres de iglesias, algunas de ellas antiguos alminares, en los núcleos del interior. 
6. LA PERCEPCiÓN DEL PAISAJE DE LA AXARQUía. REPRESENTACIONES CULTURALES Y PERCEPCIÓN SOCIAL

\subsection{EL PAISAJE DE LA AXARQUÍA EN LAS REPRESENTACIONES CULTURALES DEL PAISAJE.}

Entre las representaciones culturales del paisaje de la Axarquía, el exponente más antiguo que podemos encontrar es la vista de Vélez Málaga recogida en el Civitates Orbis Terrarum. La imagen (fig. 8) tiene como elemento central al núcleo de Vélez Málaga, extendido a los pies de su castillo, pero incorpora componentes estructurantes del paisaje de la Axarquía, como el cierre montañoso oriental, incluyendo el Boquete de Zafarraya, y, en un escalón inferior, las montańas medias silíceas, que adquieren un cromatismo diferente.

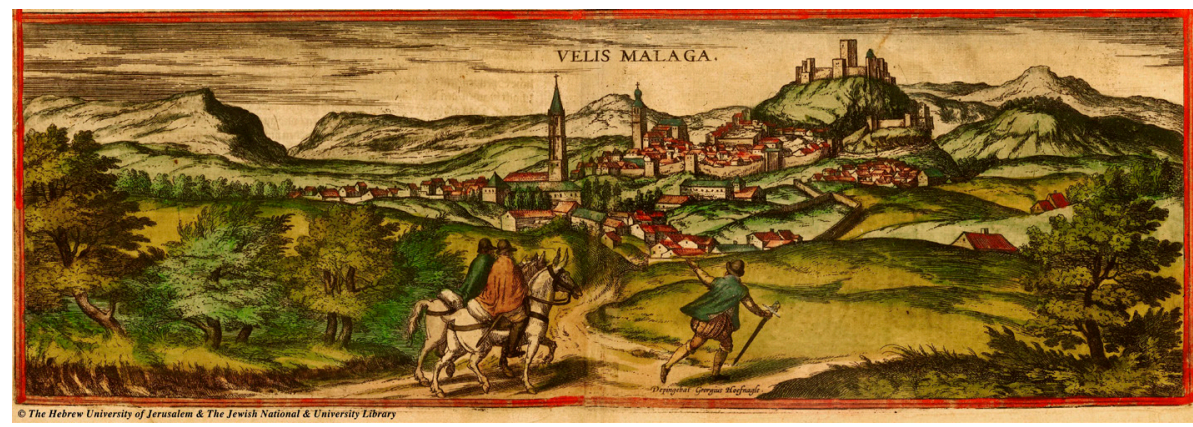

Figura 8. Vista de Vélez Málaga en Civitates Orbis Terrarum. Siglo XVI.

Más allá de esta representación, y de otras semejantes realizadas en la Edad Moderna, la mayor parte de las representaciones culturales del paisaje se sitúan ya en el siglo XX, tanto las literarias (por ejemplo, Salvador Rueda) como las fotográficas y pictóricas. Entre estas últimas cabe destacar la obra paisajística de pintores locales de prestigio, como Hierrezuelo y, de forma especial, Evaristo Guerra. Este último tiene como tema central de su obra a los paisajes más arquetípicos de la Axarquía: paisajes rurales con núcleos y llamativos cultivos arbóreos, especialmente almendros en flor (fig. 9). 


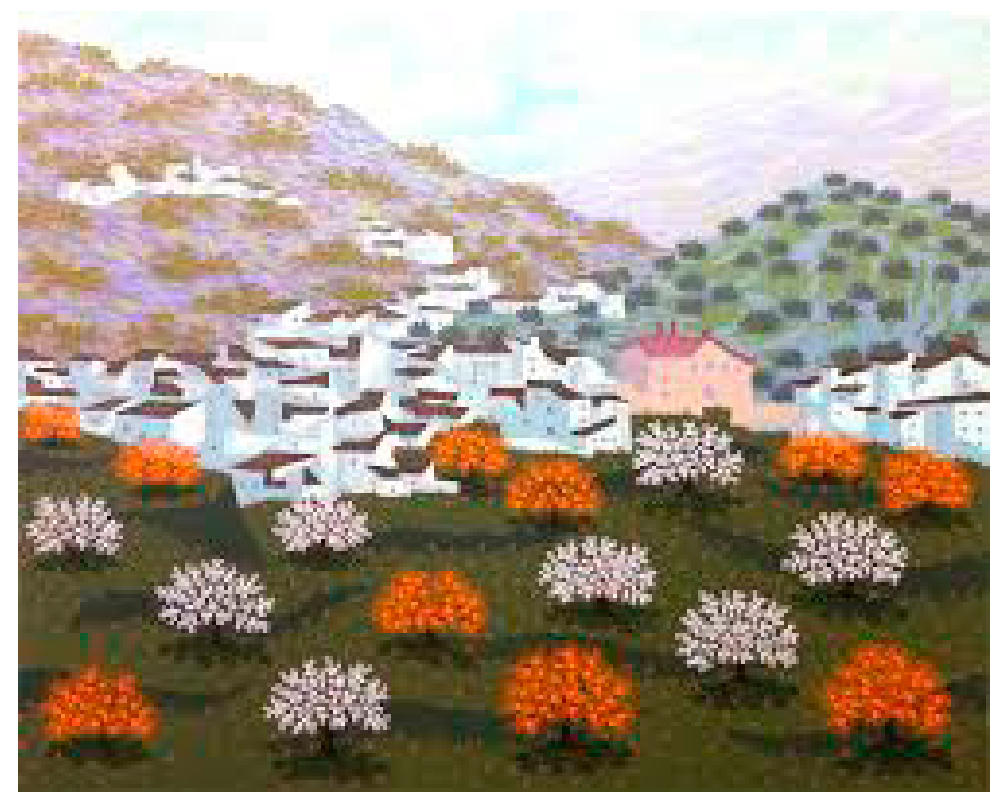

Figura 9. Evaristo Guerra: Frigiliana. Fuente: www.evaristoguerra.com

Sin duda, el desarrollo turístico supuso un impulso para las representaciones del paisaje de la comarca (Zoido y Rodríguez, 2015), al igual que un acontecimiento de gran importancia cultural: el descubrimiento de las cuevas de Nerja. Desde entonces, el paisaje de la Axarquía ha sido muchas veces reproducido en materiales promocionales, tanto los litorales como, especialmente, los interiores. Ejemplo de ello se muestran en sendas fotografías extraídas de la web de turismo de la Junta de Andalucía. En la primera de ellas (fig. 10a) se ofrece una panorámica transversal de los diversos tipos de paisaje rural: núcleos, montañas medias cultivadas y marco montañoso calcáreo; en la segunda (figura 10b) se centra en el cultivo de la vid y los paseros, en la realidad minoritarios en la comarca pero de gran importancia simbólica e identitaria. 

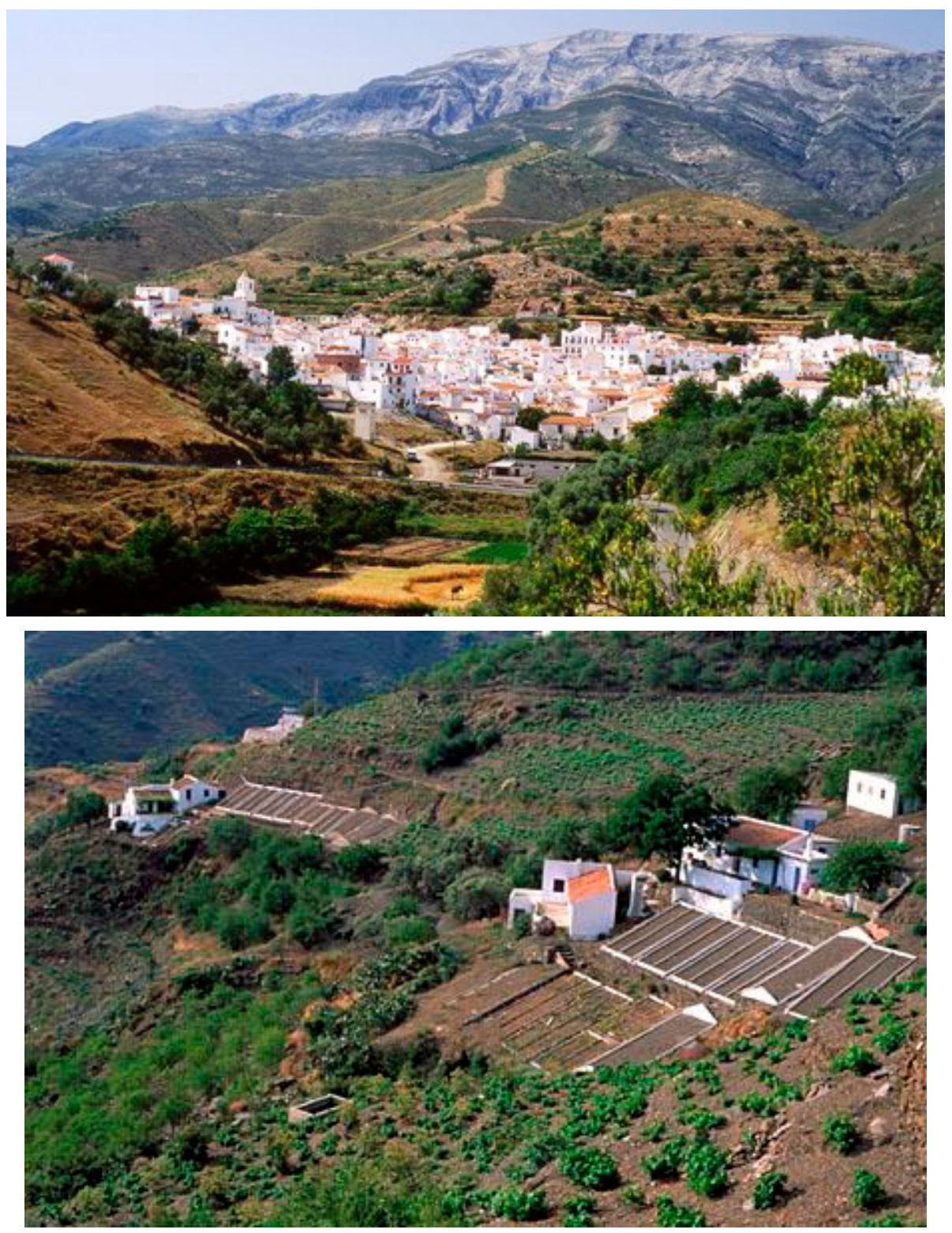

Figura 10, a y b: Imágenes de la Axarquía en la web de turismo de la Junta de Andalucía. Fuente: www.andalucia.org

El poblamiento, tanto en núcleos como en disperso, también ha constituido fuente de materiales turísticos, resaltando el carácter tradicional de las construcciones. Un ejemplo lo podemos encontrar en la portada de un folleto turístico de 1990 (ver fig. 11), en la que aparece recogida una construcción 
tradicional. Sin embargo, ya en aquella época pero especialmente en las dos décadas siguientes, las construcciones tradicionales aisladas han sido abandonadas y en muchos casos reemplazadas y multiplicadas por tipologías más contemporáneas, perdiéndose de este modo un importante acervo cultural. Pero siguen formando parte del paisaje arquetípico de la Axarquía: en la web de turismo de Andalucía sigue apareciendo ejemplos de estas edificaciones cada vez más escasas (ver fig. 12).

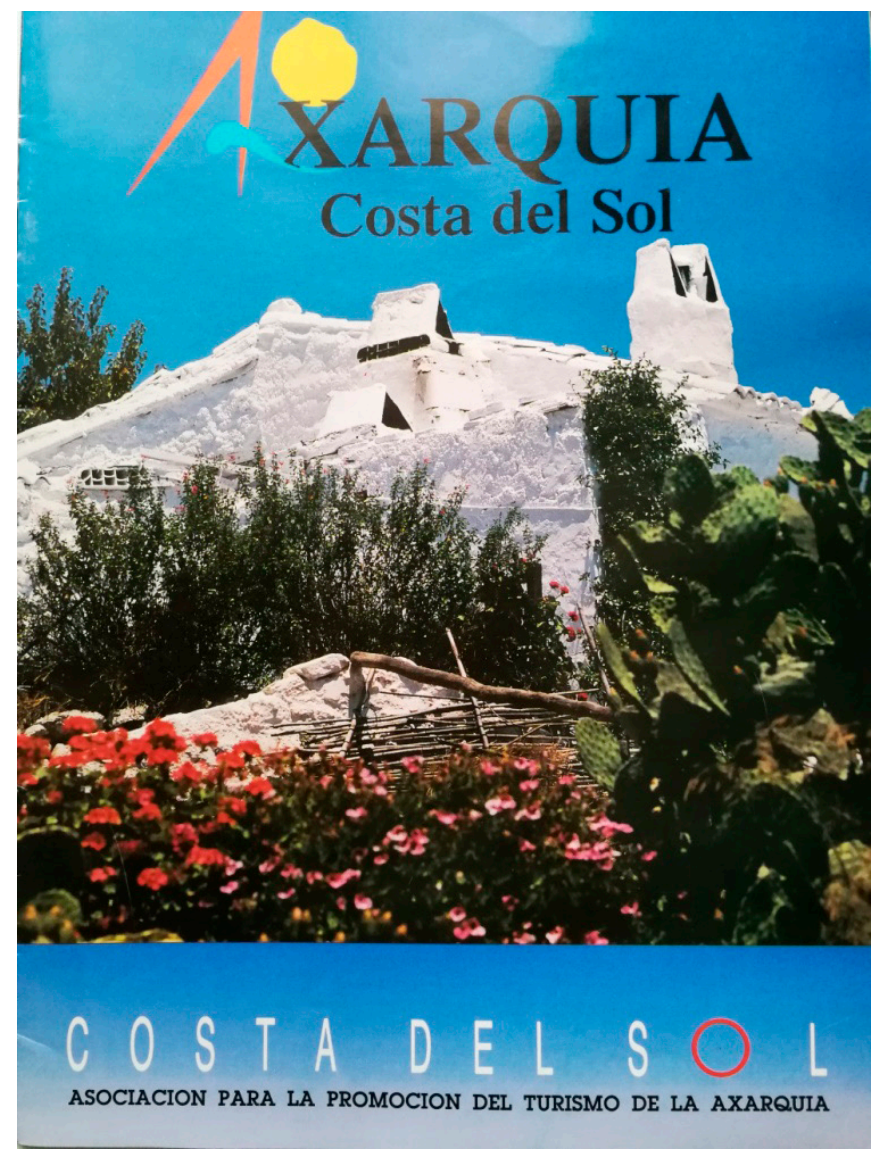

Figura 11. Portada folleto turístico de 1990. 


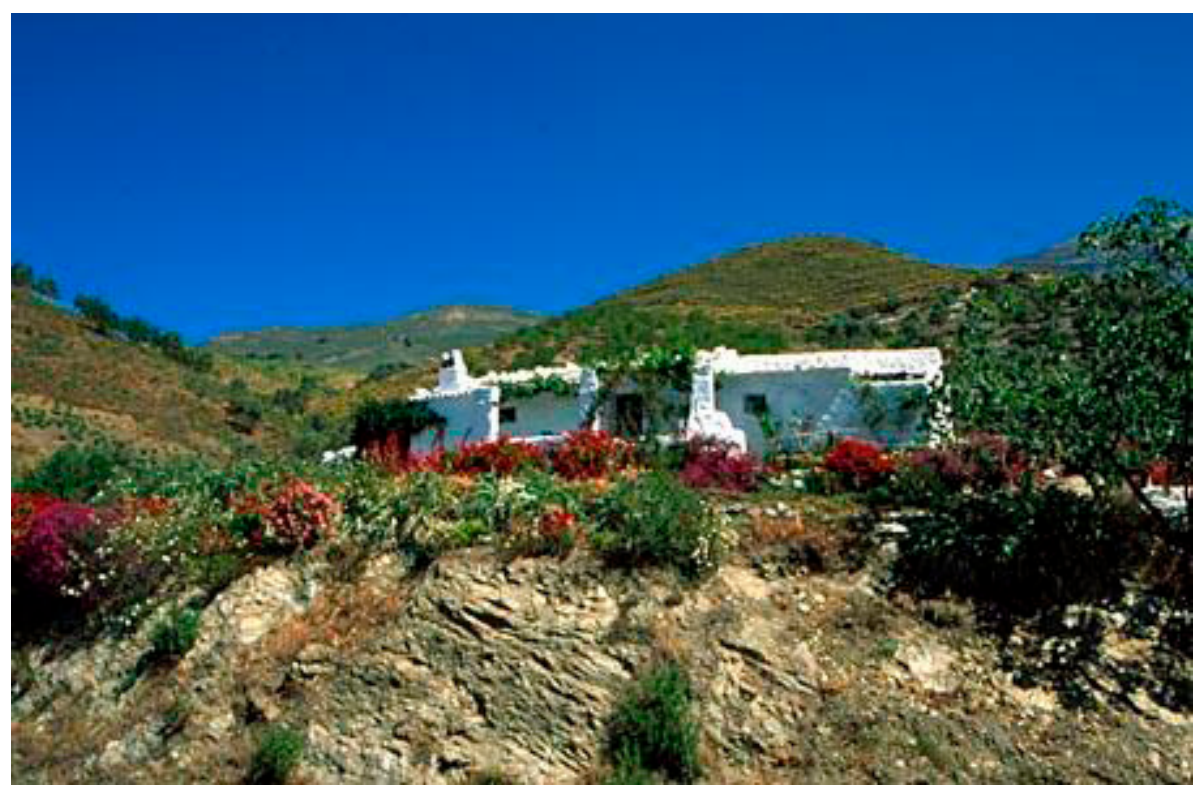

Figura 12. Imagen de construcción tradicional en la web de turismo de la Junta de Andalucía. Fuente: www.andalucia.org

\subsection{LA PERCEPCIÓN SOCIAL DEL PAISAJE DE LA AXARQUÍA.}

No son muy numerosos los estudios realizados sobre percepción social del paisaje en la comarca de la Axarquía, a través de consultas directas a grupos de población, más allá de dos referentes: el ensayo de Mérida (1997) sobre los paisajes litorales y prelitorales de la comarca y el ejercicio de participación pública realizado en el Catálogo de Paisajes de la Provincia de Málaga (Zoido y Rodríguez, 2015). Más recientemente, se ha realizado un proyecto de investigación sobre percepción social del urbanismo disperso que tenía a la comarca como área de estudio, dirigido por el autor entre 2015 y 2019 y recogido en la primera página, donde se ha abordado la realización de entrevistas y encuestas a la población que incluyen, además de preguntas específicas sobre el urbanismo difuso, ítems relativos a la percepción general del paisaje en la comarca, de los que se ofrecen algunos resultados generales. Las encuestas, 137 en total, se han realizado a diferentes grupos de población: población extranjera residente, población local y miembros de asociaciones, mientras las entrevistas pormenorizadas han sido realizadas a actores sociales de diversas categorías: gestores del territorio, empresarios, miembros de asociaciones, medios de comunicación, etc.

La situación general del paisaje en la Axarquía es contemplada de forma positiva por el el $53 \%$ de los encuestados, mientras que el $44 \%$ mantiene una posición algo más crítica, considerándolo como mejorable; únicamente sólo el $3 \%$ lo consideraba negativo. Por grupos de población, la población extranjera se 
situaba en valores próximos al promedio, mientras que las diferencias significativas en la percepción del estado del paisaje surgen entre la población local, donde la visión positiva es mayor $(63 \%)$ y los miembros de las asociaciones, más críticos, en los que el porcentaje baja al $28 \%$.

Respecto a los cambios paisajísticos experimentados en las últimas décadas, no existe una visión unánime, contemplándose unos de forma positiva y siendo mayor el rechazo en otros. Entre estos últimos, el desarrollo de los invernaderos suscita una clara censura desde el punto de vista paisajístico tanto en la encuesta como en las entrevistas, siendo este resultado coincidente con el registrado en otros estudios como el de Mérida (1997) o el de Zoido y Rodríguez (2015). Ciertamente, la elevada productividad de esta modalidad agrícola no parece ser suficiente como para ser valorados positivamente desde el punto de vista paisajístico, aunque es necesario recalcar que en la población local el rechazo es mucho menos contundente, siendo valorados positivamente por un $30 \%$ de este grupo de encuestados.

Por el contrario, la expansión de los cultivos subtropicales es valorada, en líneas generales, de forma positiva por los encuestados. Especialmente por la población extranjera, pero también por parte de la población local, que aprecia la frondosidad que adquieren estas explotaciones, que prácticamente cubren con un denso manto arbóreo un terreno de usos del suelo más extensivos, sobre todo en las laderas montañosas. Sobre estas, los subtropicales ganan en las preferencias frente a los antiguos terrenos agrícolas marginales abandonados, aunque cuando se comparan con los usos tradicionales (olivar, almendros, etc.), las preferencias se aproximan. Hay que indicar que entre los miembros de las asociaciones, habitualmente más sensibles a las cuestiones medioambientales, la atracción por los subtropicales decae, movidos sin duda por el controvertido consumo de agua de estos cultivos y por los movimientos de terreno que conllevan. De hecho, cuando se presentan imágenes con ejemplares recién plantados, y por tanto con mucho menor grado de cobertura del terreno, las preferencias bajan de forma acusada.

Un proceso territorial de indudables consecuencias paisajísticas lo representa la proliferación del hábitat disperso. Resolver qué percepción existía del paisaje en estas áreas constituía el objetivo central del estudio de percepción social realizado en el marco del proyecto. En líneas generales, las respuestas tienden a evidenciar una valoración positiva, no exenta de crítica, entre la población extranjera (residentes en este tipo de construcciones) y un claro rechazo entre los miembros de las asociaciones. Más llamativa son las respuestas de la población local, donde los porcentajes de valoración positiva en diferentes puntos de la encuesta son mucho más elevados, manifestando la existencia de una sólida corriente de atracción hacia el proceso y sus manifestaciones paisajísticas. 
Finalmente, se preguntaba a los encuestados sobre su percepción futura del paisaje en la Axarquía. A pesar de los cambios territoriales que viene experimentando la comarca, la mayoría de los encuestados se declaran, en líneas generales, optimistas, un $71 \%$, mientras que el $29 \%$ restante lo percibe de manera más pesimista. De nuevo emergen sustanciales diferencias entre los distintos grupos de población, ya que los porcentajes de visión optimistas se moderan entre la población extranjera y los miembros de asociaciones, y por el contrario se disparan hasta un $89 \%$ en el caso de la población local. De nuevo podemos comprobar cómo existe, de forma marcada en este grupo de población, una conexión entre el dinamismo económico del territorio y su percepción paisajística positiva, considerando como enriquecedoras las transformaciones paisajísticas experimentadas.

\section{Conclusiones. Entre la singularidad y el Dinamismo territorial.}

En el análisis de la situación paisajística de la Axarquía se evidencia la existencia de una tensión entre el mantenimiento de la singularidad y las transformaciones paisajísticas que producen los procesos territoriales que se vienen desarrollando en la comarca.

Aunque, por supuesto, la gestión de su paisaje no está exenta de problemas y de diferentes presiones, en los espacios protegidos de la comarca, bien por la legislación medioambiental o bien por la cultural, la situación del paisaje es, en líneas generales, satisfactoria; por el contrario, en las restantes zonas determinados procesos territoriales, sobre los que apenas existe regulación, están implicando profundos cambios paisajísticos. Esto ocurre, sobre todo, en las zonas litorales y en una parte considerable de las montańas medias, donde se concentra el desarrollo urbano, la urbanización difusa, las infraestructuras y los nuevos cultivos y técnicas agrícolas. Por el contrario, en la zona norte, en el pasillo margoso del corredor Colmenar-Periana, el menor empuje del dinamismo económico ha supuesto menores transformaciones del paisaje, que continúa teniendo una marcada base agrícola de secano.

Admitiendo la complejidad de revertir la intensidad de estos procesos territoriales en la franja litoral, el territorio que se debate entre la conservación y la transformación es la parte central de la comarca, formada por las montańas medias silíceas. No se trata de un conflicto entre naturaleza y transformaciones humanas, sino que nos encontramos ante un territorio tradicionalmente muy humanizado, en el que la tensión surge entre los patrones territoriales tradicionales y los procesos de cambio acelerado que se están produciendo. Poblamiento tradicional versus urbanización difusa, o cultivos tradicionales (vid, olivar, almendros) versus expansión agresiva de nuevos cultivos (aguacates, mangos), son dos buenos ejemplos de estas tensiones. Y no se trata de una cuestión de resistencia nostálgica: la clave de la tensión es que ese paisaje agrario tradicional representa el arquetipo 
del paisaje axárquico, y, en consecuencia, constituye uno de sus principales recursos turísticos, como se puede comprobar en la publicidad turística, y además supone un indudable componente de la identidad de una población de acentuada conciencia de singularidad. Recordemos, en este sentido, que reforzar la identidad territorial en zonas rurales constituye uno de los objetivos de la Agenda Territorial Europea 2020.

Pero, ciertamente, resolver la tensión resulta una cuestión compleja. Como hemos comprobado en los ensayos de percepción comentados, la población local percibe, en líneas generales, muchos de estos cambios paisajísticos de forma positiva, como traslación del beneficio económico que suponen. Por tanto, se hace necesario, por un lado, profundizar en el conocimiento de la percepción social del paisaje y de los procesos territoriales que están alterándolo, y por otro lado, avanzar en la explicación de los beneficios económicos y sociales que conlleva potenciar la calidad del paisaje, con la finalidad de introducir criterios paisajísticos en los procesos territoriales que previsiblemente van a continuar desarrollándose.

\section{REFERENCIAS BIBLIOGRÁFICAS}

Castellón Serrano, F. y Martínez Madrid, R. (2007). Axarquía. Patrimonio Histórico-Artístico. Málaga: CEDER Axarquía.

Benabent Fernández de Córdoba, M. (2009). La Axarquía, un paisaje en proceso de transformación. Revista PH, Instituto Andaluz de Patrimonio Histórico, $71,45-51$.

Council of Europe (2000). European Landscape Convention. Council of Europe Publications.

Gómez Moreno, M. L. (1983). Presión demográfica y transformaciones agrarias. Un caso malagueño: Casabermeja y Colmenar. Málaga: Diputación Provincial de Málaga.

Gozálvez Cravioto, C (1984). La vía romana Item Castulo-Malaca a su paso por Nerja. Jábega, 48, 3-9.

Justicia Segovia, A. (1988). La Axarquía malagueña y la costa oriental. Dos espacios agrarios contrapuestos. Málaga: Arguval.

Justicia Segovia, A. (1984). La Axarquía, los Montes de Málaga y la costa oriental. En Alcobendas, M. (Dir.). Málaga (pp. 285-326). Málaga: Enel.

Mérida Rodríguez, M. y Pardo García, S. (2010). El patrimonio paisajístico de la Axarquía. Sociedad: Boletín de la Sociedad de Amigos de la Cultura de VélezMálaga, 9, 17-26.

Mérida Rodríguez, M. (1997). El paisaje de la Costa Oriental de la provincia de Málaga. Tipos y preferencias. Málaga: Universidad de Málaga-Unicaja. 
Santiago Ramos, A. y Guzmán Valdivia, A. (2007). Axarquía. Patrimonio industrial. Málaga: CEDER Axarquía.

Senciales González, J.M. (2007). El clima en la provincia de Málaga. En Duran Valsero (coord.). Atlas hidrogeológico de la provincia de Málaga (pp. 49-58). Madrid: IGME - Diputación Provincial de Málaga.

Yus, Ramos, R. y Torres Delgado, M.A. (2010). Urbanismo difuso en suelo rústico. Málaga: GENA-Ecologistas en Acción.

Zoido Naranjo, F. y Rodríguez Rodríguez, J. (2015). Catálogo de Paisajes de la provincia de Málaga. Sevilla: Centro de Estudios Paisaje y Territorio Consejería de Medio Ambiente y Ordenación del Territorio. 